\title{
Recent advances in delivery of veterinary DNA vaccines against avian pathogens
}

\author{
Seyed Davoud Jazayeri and Chit Laa Poh*
}

\begin{abstract}
Veterinary vaccines need to have desired characteristics, such as being effective, inexpensive, easy to administer, suitable for mass vaccination and stable under field conditions. DNA vaccines have been proposed as potential solutions for poultry diseases since they are subunit vaccines with no risk of infection or reversion to virulence. DNA vaccines can be utilized for simultaneous immunizations against multiple pathogens and are relatively easy to design and inexpensive to manufacture and store. Administration of DNA vaccines has been shown to stimulate immune responses and provide protection from challenges in different animal models. Although DNA vaccines offer advantages, setbacks including the inability to induce strong immunity, and the fact that they are not currently applicable for mass vaccination impede the use of DNA vaccines in the poultry industry. The use of either biological or physical carriers has been proposed as a solution to overcome the current delivery limitations of DNA vaccines for veterinary applications. This review presents an overview of the recent development of carriers for delivery of veterinary DNA vaccines against avian pathogens.
\end{abstract}

\section{Table of Contents}

1 Introduction

2 Routes of administration for DNA vaccine delivery

3 Vectors for delivery

4. Biological carriers

4.1 Gram-negative bacteria as potential carriers for DNA vaccines

\subsubsection{Salmonella}

4.2 Gram-positive LAB

5 Physical carriers

6 Conclusions

References

\section{Introduction}

Vaccines have been effective against infectious diseases in animals and have successfully controlled and/or eradicated major animal pathogens. Based on the guidelines proposed by the Royal Society's report on infectious diseases of livestock in 2002, UK, the characteristics of an ideal vaccine are:

- provides broad-spectrum protection against all isolates of the virus in all the affected species, preventing virus carriage and the possibility of shedding and transmission;

- stimulates the level of immunity necessary to drive effective and long-lasting immune responses;

- inexpensive to manufacture and simple to administer;

- in the case of live attenuated vaccines, reversion to virulence has to be avoided;

- has a long shelf life and is heat stable;

- allows discrimination between infected and vaccinated animals; and

- provides strong levels of maternal immunity. 
Nevertheless, there is no single vaccine that has all the above characteristics. The use of vaccines to control disease is based on assessing the risks and evaluating the benefits following vaccination. Generally, genetic vaccines are composed of either DNA (as plasmids) or RNA (as mRNA) that is taken up and translated into proteins by cells of the vaccinated animals. Since there are limited reports on RNA vaccines compared to the extensive literature on DNA vaccines, genetic vaccines are generally referred to as plasmid DNA antigen-expression systems. Genetic immunization, also termed DNA immunization, is a recent vaccine technology utilizing eukaryotic expression vectors encoding antigens [1].

Wolff et al. first demonstrated that direct intramuscular (IM) injection of plasmid DNA was able to generate the expression of the plasmid-encoded antigen in a murine model [2]. To date, DNA vaccines have been successfully licensed for use against West Nile virus in horses [3], infectious haematopoietic necrosis in schooled salmons [4], and canine melanoma in dogs [5], as well as Clynav against pancreas disease infection in Atlantic salmon [6]. Moreover, the first commercial DNA vaccine against H5N1 in chickens has recently been conditionally approved by the United States Department of Agriculture (USDA), which targets highly pathogenic H5 avian influenza [7].

The first DNA vaccine that was studied in poultry in 1993 was directed against avian influenza virus (AIV) [8]. Immunization with DNA vaccines has had some success that could be attributed to their advantages over conventional vaccines. Despite the success of some DNA vaccines in small animal models in veterinary applications, there are still limitations in plasmid delivery and lack of immunogenicity in large animal models. To improve the immunogenicity of DNA vaccines, adjuvants have been co-administered in vivo with DNA vaccines. It is also possible to incorporate an immunomodulatory adjuvant into the plasmid and co-express the adjuvant gene. Immunomodulatory genes, including cytokines (IL15, IL18) [9], Esat-1 [10], MDP-1 [11], HMGB1 $\Delta C$ [12] or HSP70 [13, 14], were found to enhance the humoral and cell-mediated immunity of AIV DNA vaccines. In addition, recent advances in the optimization of antigens carried in plasmids [15]; novel delivery methods, such as electroporation [16] or jet injections [17]; targeting of antigens to antigen-presenting cells (APCs) [18]; and co-delivery with biological [19] and nanoparticle [20] carriers have led to a substantial improvement in DNA vaccine efficacy in poultry.

Poultry DNA vaccines have been developed against several viral, bacterial and protozoan diseases. Promising results have been obtained and full protection (100\%) elicited against poultry diseases, such as AIV in chickens and quails, duck Tembusu virus (DTMUV), infectious bursal disease virus (IBDV) and Newcastle disease virus (NDV) in chickens (Table 1). Based on the data summarized in Table 1, approximately $76 \%$ of poultry DNA vaccine studies were trialed in chickens, $13 \%$ in ducks, $9 \%$ in turkeys and just $2 \%$ in quails (Figure 1A). The efficacy of poultry DNA vaccines is affected by the age of the hosts, number of vaccination(s), vehicles and adjuvants, different routes of delivery and immunity against different pathogens (Table 1). Low in vivo efficacy contributed by factors such as the delivery system has always been the challenge for developing DNA vaccine utilization in poultry. Thus, this review is aimed at discussing the development of delivery systems for DNA vaccines in poultry. The benefits and pitfalls of using each delivery system will be discussed.

\section{Routes of administration for DNA vaccine delivery}

Effective DNA vaccine delivery is required to induce a strong and long-lasting immune response that can produce high and sustained levels of antigen production at targeted sites. Delivery routes of DNA vaccines can be generally grouped into those that are mucosal or systemic. Relative proportions of different administration routes of inoculation in poultry were calculated from the data summarized in Table 1 and presented in Figure $1 \mathrm{~B}$. The most extensively used routes for the delivery of poultry DNA vaccines include IM (55\%), oral (23\%), in ovo (IO) (11\%), eye drop (ED) (4\%) and intranasal (IN) (3\%) (Figure 1B). Although some new delivery methods and routes are under development or being tested in poultry, conventional IM injection is still considered the dominant DNA vaccine delivery route. The majority of poultry DNA vaccines (approximately $55 \%$ ) were applied as naked DNA through IM injection into the leg, chest or thigh muscles of poultry, and some promising results have been obtained. Full protection against a highly virulent H5N1 AIV infection was elicited in quails by IM immunization of a DNA vaccine encoding the $\mathrm{H} 5$ gene [21]. Ideally, DNA vaccine delivery should not be invasive [22]. However, most of the parenteral routes commonly used were needle-based deliveries and thus might cause complications in vaccinated chickens [23]. Compared with the parenteral routes, oral administration in poultry is faster and much easier to administer for mass application without requiring highly trained manpower and no risk of needle-stick injury or cross-contamination [24]. Oral immunization is able to induce mucosal immune responses and was performed as the second most popular route, with approximately $23 \%$ of poultry vaccinations. 


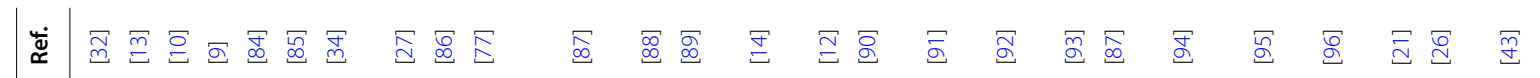

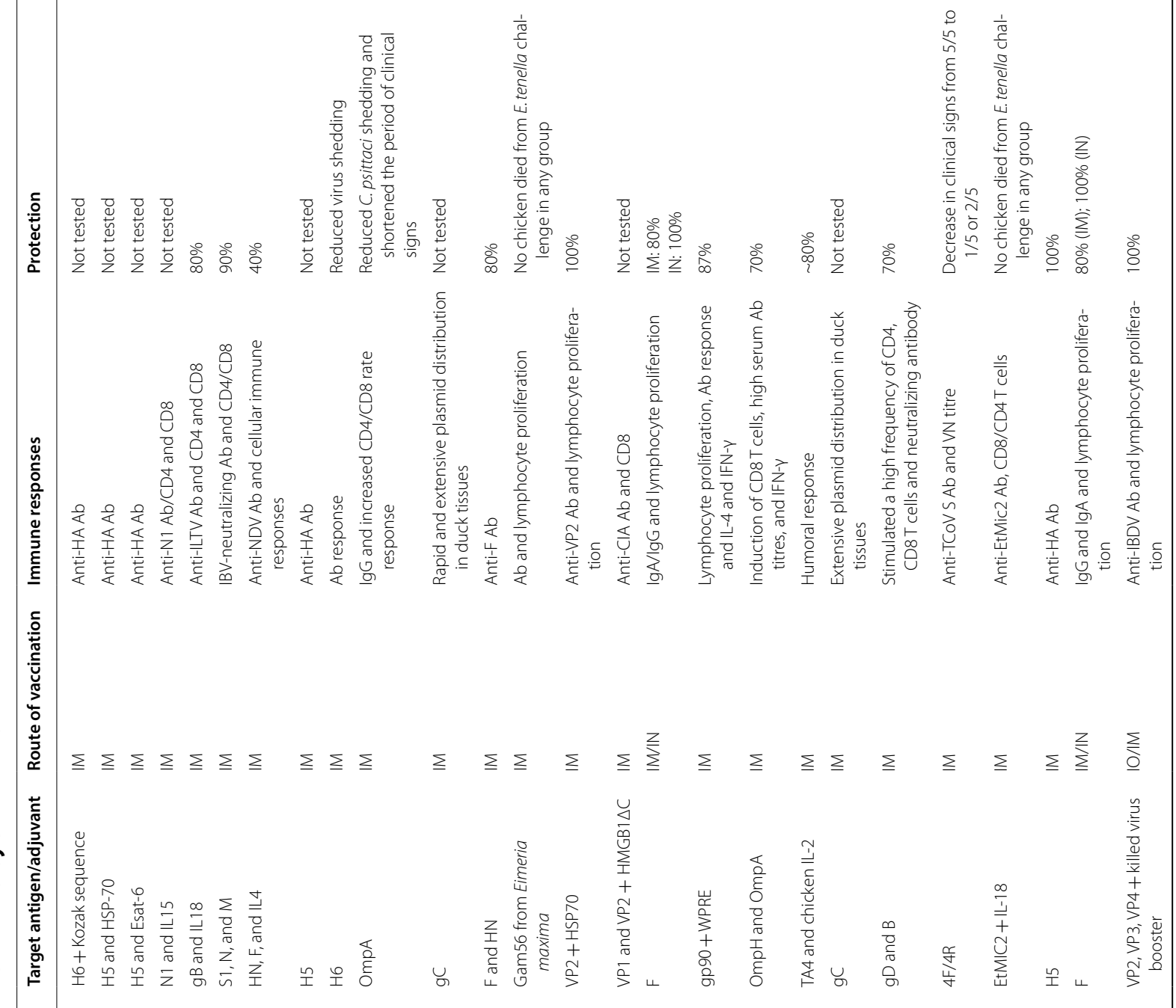

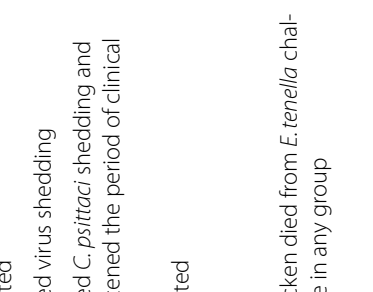

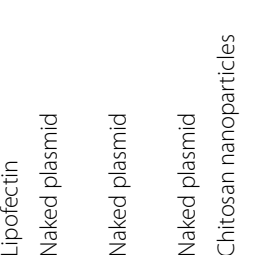

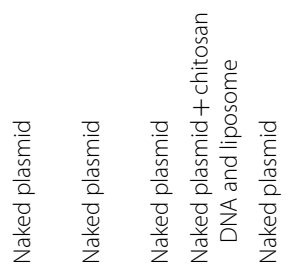

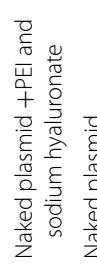

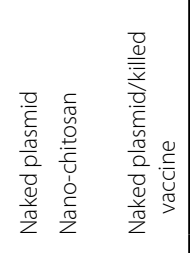

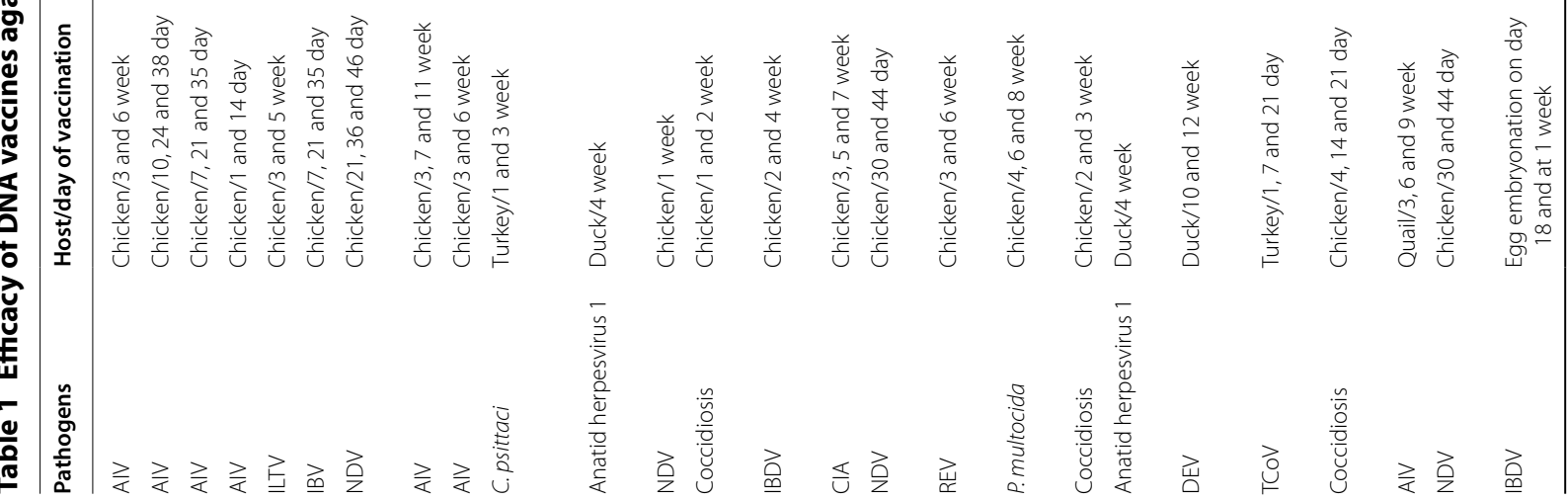




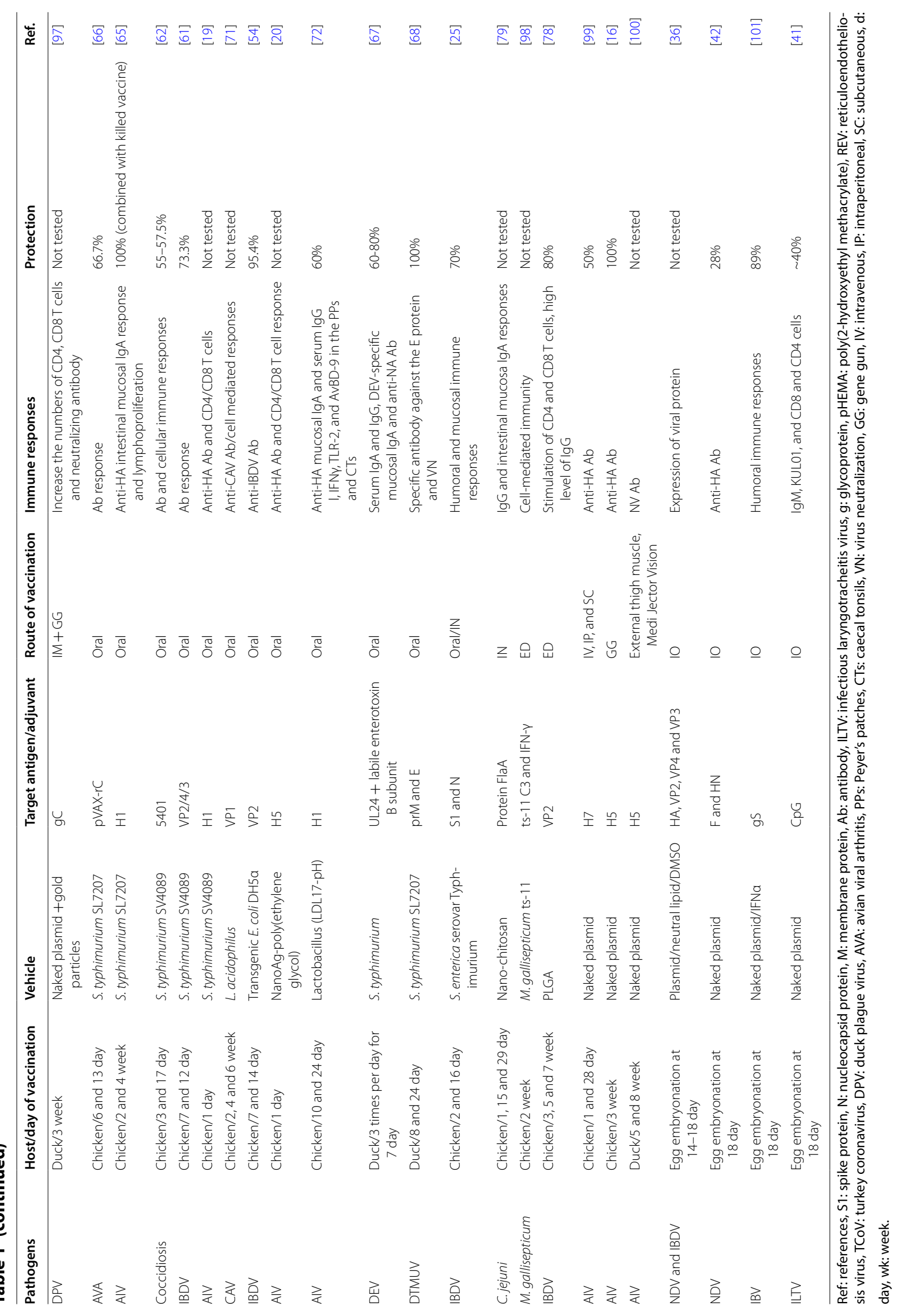


A

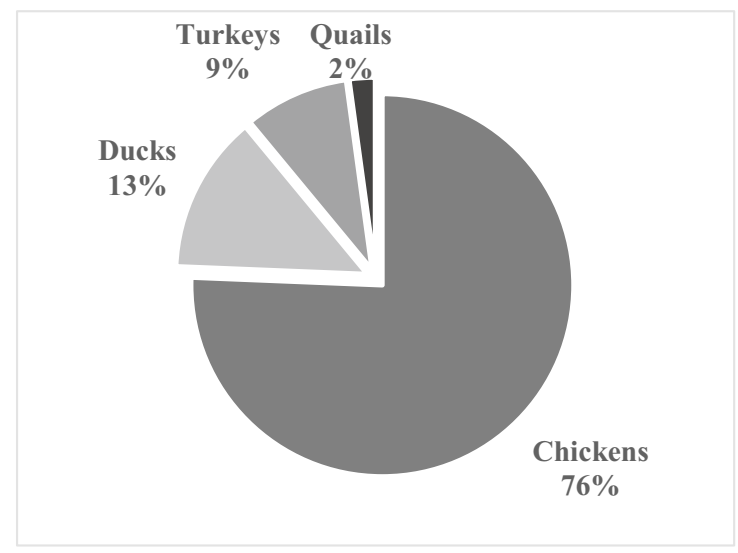

B

C

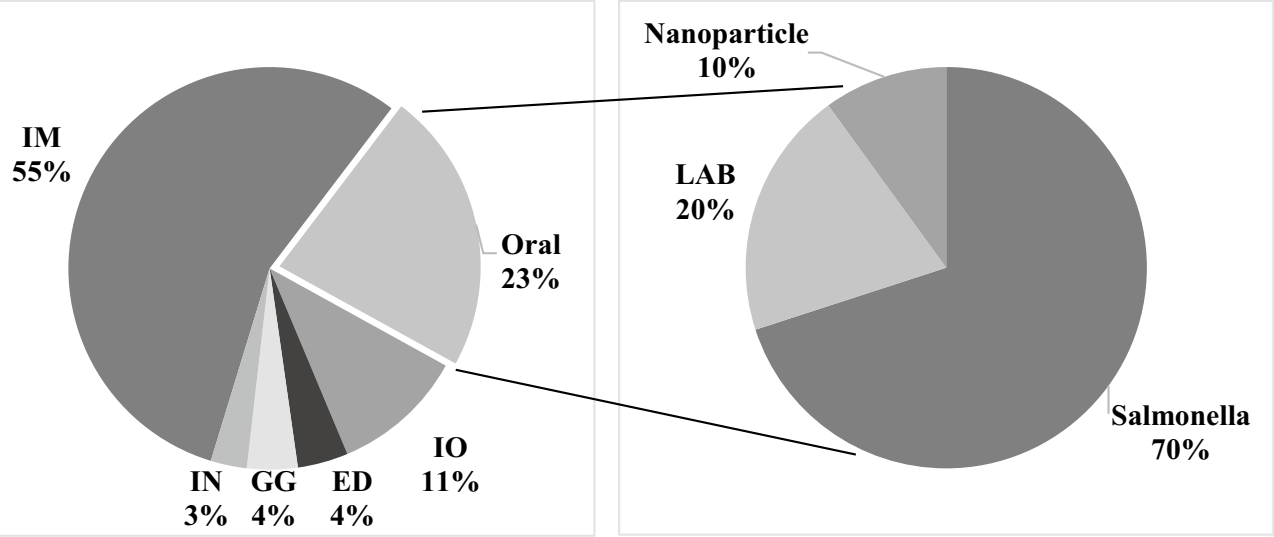

Figure 1 Different poultry DNA vaccination models, routes and carriers. A Relative proportions of DNA vaccine studies performed in poultry. B Relative proportions of different routes of administration in poultry. C Salmonella spp., LAB spp. and nanoparticles play major roles in oral delivery of DNA vaccines. IM: intramuscular, IO: in ovo, ED: eye drop, IN: intranasal, GG: gene gun, LAB: lactic acid bacteria.

IO, which is specific to poultry, is the third most popular route of vaccination, at approximately $11 \%$ (Figure $1 \mathrm{~B}$ ).

Encapsulation of naked DNA with a carrier has been proposed as a solution to improve the controlled release of antigens that could increase the efficacy of DNA vaccines. Regardless of live, attenuated, killed or DNA vaccines, noninvasive vaccinations, including IN and oral delivery, could reduce stress, pain and cost of vaccinations and increase the safety of vaccination in large flocks of birds.

Furthermore, successful IN and oral delivery tend to raise better mucosal immunity than the other routes against poultry respiratory viruses, such as infectious bronchitis virus (IBV) [25], NDV [26], and AIV [19]. Thus, the design of carriers should help improve the efficacy and stability of DNA vaccines for IN or oral delivery. The carrier must be able to resist degradation and attack by the immune system and have sufficient safety profiles to become a successful delivery system.

\section{Vectors for delivery}

Regardless of the choice of route, the low efficiency of traditional naked DNA vaccines has always been considered one of the main obstacles. To overcome this problem, improved expression vectors with more efficient promoters and the use of adjuvants were proposed to improve the efficacy of DNA vaccines in poultry. Lee et al. demonstrated that the use of the pCI-neo HA plasmid with the cytomegalovirus (CMV) promoter could effectively boost the antibody response against influenza virus in chickens [27]. Most of the plasmids that have been successfully used for poultry DNA vaccine development were mainly the same as those used in mammalian DNA vaccines, and few plasmids, such as pCAGGS (antigen transcription is under control of 
the chicken $\beta$-actin promoter), were specifically developed and used for poultry applications [28].

Codon optimization is based on the selection of codon triplets that have the highest tRNA utilization frequency in the cytoplasm, which can increase translation rates and mRNA stability. Successful DNA vaccination requires high expression of the antigenic gene(s) in the host, and this method is usually used to elicit foreign protein production [29]. The Kozak sequence plays a significant role in the initiation of a translation process in mammalian cells by increasing the chance of ribosome recognition of the AUG start codon in the transcription process [30].

In addition, the Kozak sequence was also found to enhance the expression of a DNA vaccine after immunization. However, the efficacy of a DNA vaccine with the Kozak sequence for both Marek's disease (MD) and AIV was not well supported in two reports [31, 32]. Oligodeoxynucleotides rich in cytosine-guanosine deoxynucleotide (CpG) motifs were also found to enhance the innate immunity of chickens and effectively protected $(\sim 80 \%)$ against S. typhimurium septicaemia upon challenge [33]. In addition to using improved expression vectors and promoters, the development of multivalent DNA vaccines enhanced cell-mediated immunity. Sawant et al. constructed a bivalent DNA vaccine simultaneously expressing the $\mathrm{HN}$ and $\mathrm{F}$ antigens of NDV with the chicken immunomodulatory IL-4 gene. Chickens inoculated via the IM route displayed an increase in NDV-specific antibodies and cell-meditated immunity. The DNA vaccine conferred protection to $40 \%$ of chickens against NDV upon challenge [34].

Fusion of the M. tuberculosis HSP70 or Esat- 6 genes with the $\mathrm{H} 5$ gene of AIV H5N1 was also found to enhance the antibody response in chickens $[10,13]$. In addition to the fusion of two genes, Lim et al. demonstrated that codelivery of N1 and IL-15 in 2 different plasmids induced higher humoral and cell-mediated immunity in chickens than vaccination with $\mathrm{N} 1$ alone [9]. Coexpression of chicken IL-2 and IL-7 enhanced the humoral and cellmediated immunity as well as the protective efficacy of a VP2-expressing DNA vaccine against IBDV in chickens [35]. In addition, the DNA adjuvant neutral lipid with DMSO was reported to be suitable for IO vaccination with NDV and IBDV viral proteins [36]. Progress has been made towards the development of many monovalent DNA vaccines in poultry medicine, although the desirable practical farm DNA vaccine should be effective against multiple species. Novel multivalent $\mathrm{T}$ cell epitope DNA vaccines against four Eimeria species were constructed, and animal experimentation showed effective protection against all four species, E. tenella, E. necatrix, E. maxima and E. acervuline, in chickens [37].
IO delivery of CpG DNA has been shown to reduce bacterial infections with $S$. enteritidis, S. typhimurium and $E$. coli in chickens $[38,39]$. It was found to mediate an antiviral response against influenza, which correlated with a macrophage response in the lungs [40]. In another trial, IO delivery of CpG DNA increased recruitment of IgM, KUL01, and CD8 and CD4 T cells at day 1 posthatching in the trachea, lungs, duodenum, large intestine, spleen and bursa of chickens [41]. However, these modifications could only partially solve the low efficacy of DNA vaccines because the APCs were still not specifically targeted, and the encoded antigens were not delivered to the target site to produce sufficient mucosal or organ-specific immunity.

The efficacy of protection conferred by naked plasmids, with a few exceptions, was lower than $100 \%$. For example, a naked plasmid carrying the $\mathrm{F}$ and $\mathrm{HN}$ genes of NDV, when administered through the IO route, could only confer protection to $28 \%$ of chickens [42]. The efficacy conferred by other naked plasmids carrying antigens against AIV, ILTV, IBV, REV, and DEV was reported to range from 50 to $90 \%$ protection. However, in another example, a naked plasmid carrying the $\mathrm{H} 5$ antigen against AIV was able to confer $100 \%$ protection when delivered by the gene gun (GG) in chickens (Table 1). Park et al. demonstrated that priming with a DNA vaccine encoding the VP2, VP3, and VP4 antigens through the IO route and boosting with IM injection of a killed IBD vaccine completely protected chickens against a highly virulent IBDV [43].

\section{Biological carriers}

Bacteria have been described as "tiny programmable robot factories" for use in the delivery of DNA vaccines against various diseases (viral, bacterial and parasitic) [44]. The first report of in vitro gene transfer from bacteria to mammalian cells was reported over 30 years ago by Walter Schaffner, where tandem copies of the SV40 virus genome were transferred into co-cultured mammalian cells using laboratory strains of $E$. coli [45]. Bacteriabased DNA delivery systems are able to replicate in the host and, by carrying their own immunostimulatory factors, could elicit immune responses not only against the plasmid-encoded foreign antigens but also against the bacterial carrier itself $[46,47]$. Briefly, bacteria as poultry DNA vaccine carriers are divided into gram-positive (non-pathogenic) and gram-negative strains (attenuated pathogenic bacteria).

\subsection{Gram-negative bacteria as potential carriers for DNA vaccines}

There are some gram-negative pathogenic bacteria, such as E. coli and Salmonellae species, that have been 
isolated and used for DNA vaccine delivery in poultry. The trafficking of intracellular gram-negative bacteria can be divided into intraphagosomal and intracytosolic pathways. With regard to localized infections of bacteria in host cells, enteropathogenic bacteria are used as DNA vaccine carriers, and these can be divided into (1) extracellular pathogens, such as E. coli or Yersinia spp. (Y. pseudotuberculosis and Y. enterocolitica); (2) intraphagosomal bacteria, such as Salmonella spp.; and (3) intracytosolic bacteria, such as Shigella spp. and Listeria monocytogenes (Figure 2) [48-53]. Oral immunization of chickens with a DNA vaccine encoding the VP2 gene of IBDV carried by a transgenic E. coli DH5 $\alpha$ resulted in 95.4\% protection [54].

\subsubsection{Salmonella}

Salmonella, as a non-host-specific intracellular bacterium, is commensal in poultry and can persist in the gastrointestinal (GI) tract. Different Salmonella serotypes derived from a wide range of hosts can infect poultry [55]. Therefore, avian species can be infected by host-specific and non-host-specific Salmonella serotypes. Avian systemic salmonellosis is characterized by three separate phases: invasion of Salmonella via the GI tract, establishment of infection in macrophages and subsequent clearance of the infection by the immune system. Otherwise, the birds develop the subclinical phase of salmonellosis and die [56].

Salmonella has a close relationship with poultry and has been evaluated as a live carrier for inducing protective responses to a wide variety of infections due to its ability to improve the efficacy of a vaccine through induction of mucosal and internal organ immunity [57]. Salmonella can invade, survive and multiply in APCs (macrophages), which are the critical characteristics of Salmonella as a carrier for vaccine development. Moreover, live attenuated Salmonella can release transformed plasmids through an unknown mechanism into the eukaryotic cytoplasm (Figure 2) [58, 59]. Hence, Salmonella is a promising carrier in poultry DNA vaccine development.

Salmonella is able to orally infect animals and humans. Following ingestion, a proportion of the bacteria can resist the low $\mathrm{pH}$ of the GI tract and reach the ileum and the caecum; then, Salmonella can invade the mucosa by multiplication in the sub-mucosa and in Peyer's patches (PPs). In young birds with an immature immune system, extensive replication of bacteria occurs in the caecum [60].

Various attenuation methods have been applied to reduce the pathogenicity of $S$. typhimurium, which retained their invasive ability and could deliver a heterologous plasmid into mammalian cells. S. typhimurium SV4089, a double mutant $\left(\mathrm{Dam}^{-}\right.$and $\left.\mathrm{PhoP}^{-}\right)$of wild-type

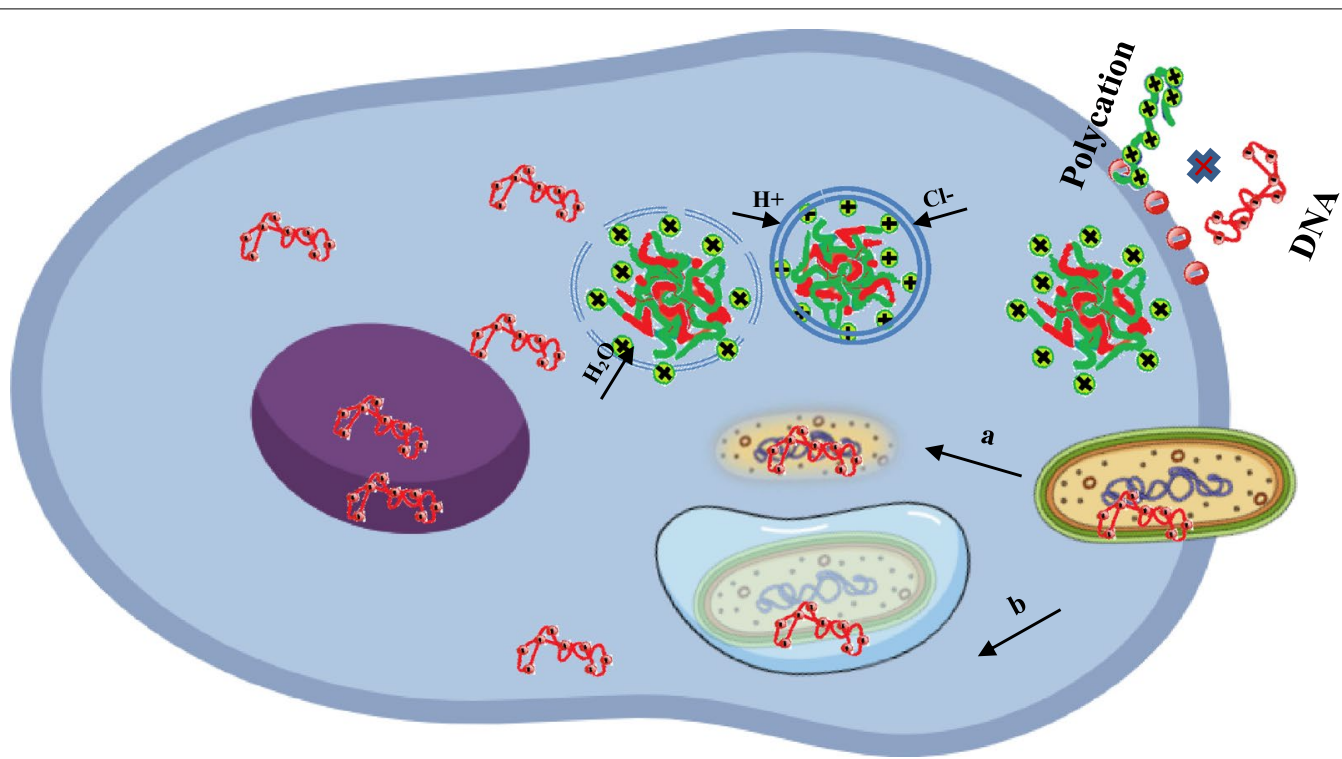

Figure 2 Principles of different carriers for DNA vaccine delivery to host cells. (1) Bacterial-mediated delivery. (a) Bacteria, such as $L$. monocytogenes, E. coli, and S. flexneri, carrying a recombinant plasmid invade host cells, escape from the vacuole system, then die in the cytosol and release the plasmid [102]. (b) Bacteria, such as Salmonella, first invade the host cells, remain in the vacuole, then die due to metabolic attenuation and release the recombinant plasmid into the cytosol [102]. (2) Polycations are able to compress the molecular size of plasmids into compact structures by converting the negative charges to positive. The high surface cationic charge of an encapsulated plasmid mediates both size condensation and buffering capacity that diminish the requirement for the addition of endosomolytic agents. Buffering leads to osmotic swelling, membrane lysis and subsequent plasmid release [103]. 
S. typhimurium SL1344, is an attenuated Salmonella strain that has been used extensively as a carrier for DNA vaccines in different animal models. Studies have shown that S. typhimurium SV4089 is not orally pathogenic to chickens at a dose level as high as $10^{10} \mathrm{cfu} / \mathrm{mL}[61,62]$, while the oral LD50 of wild-type SL1344 in chickens is $\sim 10^{4} \mathrm{cfu} / \mathrm{mL}$ [63]. The live attenuated S. typhimurium SV4089 provided a unique alternative in terms of safety and in vitro and in vivo stability of transfected plasmids. DNA vaccines are inexpensive to produce in large doses and are easily detected and monitored after oral inoculations into the host. Furthermore, attenuated S. typhimurium SV4089 was able to invade and pass through the various organs of inoculated chickens, such as the liver, spleen, and caecum, without showing evidence of systemic infection [64].

Attenuated S. typhimurium has been used as a carrier for DNA vaccines against different pathogens in poultry. In one study, oral administration of chickens with the attenuated S. typhimurium SV4089 containing pcDNA3/E. tenella 5401 antigen showed strong humoral and cellular immunity, with partial protection (55-57.5\%) against challenge from E. tenella [62]. Li et al. demonstrated that oral administration of chickens with the attenuated S. typhimurium SV4089 containing the complete polyprotein (VP2/4/3) of IBDV also offered $73.3 \%$ protection against challenge with a virulent IBDV [61]. In another study, Jazayeri et al. showed that a single oral immunization of chickens with $10^{9} \mathrm{cfu} / \mathrm{mL} S$. typhimurium SV4089 containing a eukaryote expression vector encoding the haemagglutinin (HA) gene of $\mathrm{H} 5 \mathrm{~N} 1$ did not produce any clinical manifestations. Orally vaccinated chickens showed anti-H5 antibody production, increased CD4/CD8 $\mathrm{T}$ cell levels and mixed proinflammatory/Th1-like cytokine responses against AIV, which was important for viral clearance [19].

In addition to the attenuated S. typhimurium strain SV4089, another attenuated S. typhimurium strain, SL7207, was also studied as a carrier for DNA vaccines. Pan et al. showed that oral vaccination of white leghorn chickens with an HA DNA vaccine carried by the attenuated S. typhimurium SL7207 and boosted with a killed H9N2 vaccine was able to confer $100 \%$ protection against $\mathrm{H} 5 \mathrm{~N} 1$ following challenge, with no virus shedding or clinical signs [65]. Wan et al. used $1.0 \times 10^{10} \mathrm{cfu} / \mathrm{mL} S$. typhimurium SL7207 as a carrier for oral vaccination of chickens against avian reovirus (ARV) by using the $\sigma \mathrm{C}$ protein. The results showed high levels of antibody production as well as protection of $66.7 \%$ of chickens against ARV challenge [66]. In addition to vaccinating chickens, oral DNA vaccination against duck enteritis virus (DEV) administered by the attenuated S. typhimurium SL7207 carrier co-expressing UL24 (core herpesvirus gene) and $E$. coli heat labile enterotoxin B subunit (LTB) as a mucosal adjuvant was able to induce effective systemic and mucosal immune responses and showed $60-80 \%$ protection of the ducklings [67]. Moreover, oral delivery of the Salmonella SL7207 strain carrying a DNA vaccine (pVAX1-SME) encoding the envelope proteins prM and E of DTMUV displayed strong immunogenicity and provided protection to $100 \%$ of ducks against DTMUV infection. Ducks orally vaccinated with this DNA vaccine were protected from lethal DTMUV infection. Oral administration of the DTMUV vaccine provided a fast vaccine delivery strategy and was economical for large-scale clinical applications [68]. Jiao et al. reported that a DNA vaccine encoding the $\mathrm{S} 1$ and $\mathrm{N}$ genes delivered by S. enterica serovar Typhimurium via the oral and IN routes could induce humoral and mucosal immune responses and conferred $70 \%$ protection against IBV in chickens [25].

\subsection{Gram-positive LAB}

LAB (Lactococcus, Streptococcus, and Lactobacillus) are nonsporulating, have low $\mathrm{G}+\mathrm{C}$ content and are nonpathogenic food-grade bacteria. They are an excellent candidate for functioning as adjuvants, immunostimulators and live antigen carriers to deliver antigens and cytokines at the mucosal level [69]. Dieye et al. characterized L. lactis as a potential vehicle for protein delivery (VP2 and VP3), serving as a live mucosal vaccine against IBDV in chickens [70].

Moreover, Moeini et al. showed that L. acidophilus carrying the VP1 protein of chicken anaemia virus (CAV)induced neutralizing antibodies and Th1 cytokines against CAV in orally vaccinated chickens and suggested that Lactobacilli could also be used as a potential carrier for oral immunization of chickens [71]. In another study, Wang et al. demonstrated oral vaccinations of chickens with a recombinant lactobacillus (LDL17-pH), which expressed avian HA1 protein and could significantly increase the specific mucosal anti-HA1 IgA levels and anti-HA1 serum IgG levels. The chickens were protected at a level of $60 \%$ against lethal challenge with a H5N1 virus [72].

\section{Physical carriers}

Physical approaches are the most commonly employed for DNA vaccine delivery. However, physical carriers need to successfully permeate the cell membrane of the target cell and release the DNA vaccine into the cytoplasm. The polycation-based delivery system is a promising approach for non-viral delivery because its molecular entity can be modified to fine tune and change its physicochemical properties. Since DNA is a large molecule (up to $1 \mu \mathrm{m}$ in length), is negatively charged and, as a general rule, the plasma membrane of living cells is 
proportionately lipophilic and is also negatively charged, it is expected that the cell membrane could act as a barrier for large-sized polynucleotides. In addition, naked DNA associates poorly with the cell membrane $[73,74]$.

Polycations have been used to address the problems of changing the negative charges of nucleotides to positive and compressing the molecular size of the plasmid into compact structures that are necessary for transfecting nucleotides into most types of eukaryotic cells (Figure 2). It is likely that an encapsulated DNA with a slightly positive charge could interact electrostatically with the cell membrane and then be internalized. The adsorption of DNA to the surface of positive polymers during electrostatic interactions plays a major role in improving the efficiency of DNA vaccines. More significantly, cationic polymers on the nano-scale have received heightened attention because they further enhanced the chemical stability of DNA vaccines and induced enhanced immune responses since the uptake of nanoparticle carriers with DNA vaccines into immune cells, such as dendritic cells (DC), was highly effective [75].

One of the cationic nano-polymers is nano-polyethyleneimine (PEI), which is able to electrostatically bind plasmid DNA (pDNA) and condense it into positively charged molecules, which can be taken up by cells more effectively than naked DNA. Among the PEI types, branched PEI was found to be more effective and stable than linear PEI in delivering the ompA gene to protect against Chlamydophila psittaci infection. Branched PEI was able to activate both humoral and cell-mediated immunity post vaccination. This effect might be contributed by PEI to deliver the DNA that activated APCs, such as DCs [76]. However, the vaccination could only help to reduce $C$. psittaci shedding and shorten the period of clinical signs in infected chickens but failed to raise sufficient protection against challenge [76, 77]. In addition to PEI, poly(lactide-co-glycolide) (PLGA) was also found to be effective, as it could prolong and promote sustainable release of DNA, which was taken up by APCs. Both PEI and PLGA were found to be effective in delivering the VP2 gene of IBDV and elicited both humoral (IgG) and cell-mediated immunity (CD4/CD8). Negash et al. used PLGA-PEI macroparticles adsorbed with a recombinant plasmid carrying the VP2 gene and showed that immunization of chickens could improve the efficacy of the IBDV DNA vaccine to prevent both morbidity and mortality in up to $80 \%$ of birds [78].

Other biomaterials, such as chitosan, have also been used as carriers for poultry DNA vaccines. White leghorn chickens were used as a model for IN immunization with chitosan/DNA nanoparticles, which carried the FlaA gene of $C$. jejuni. They produced significantly increased levels of IgG antibodies against $C$. jejuni and intestinal mucosal antibodies (IgA) [79]. Meanwhile, Zhang et al. successfully prepared spherically shaped chitosan nanoparticles with mean diameters between 100 and $200 \mathrm{~nm}$ and a positive surface charge, which could protect DNA against DNase I degradation. Plasmid DNA containing the $\mathrm{HN}$ and chicken IL-2 genes encapsulated with chitosan nanoparticles showed improved DNA vaccine efficacy and elicited haemagglutination inhibition (HI) antibody titres and IFN- $\gamma$ against NDV challenge in chickens [80]. Recently, Gong et al. also successfully developed chitosan nanoparticles (spherical shape and approximately $200 \mathrm{~nm}$ ) to encapsulate a $p t f A$-DNA vaccine against Pasteurella multocida, with an encapsulation efficiency of $95.3 \%$, and the formulation effectively resisted DNase degradation. IM vaccination of the encapsulated $p t f A$-DNA vaccine into 4-week-old chickens induced higher antibody concentrations and lymphocyte proliferation than naked DNA and conferred $68 \%$ protection, compared to the $56 \%$ achieved by naked DNA [81]. IN and IM immunizations of a DNA vaccine encoding the $F$ antigen of NDV encapsulated with chitosan nanoparticles induced $100 \%$ and $80 \%$ protection in chickens, respectively [26].

In addition to higher solubility and penetration into the cell, nanoparticles also provided the flexibility to be conjugated with other nanomaterials to further increase the specificity and efficacy of delivery. Moreover, Jazayeri et al. prepared green silver nanoparticles (nanoAg) with poly-ethylene glycol for delivery of the H5 gene of AIV into primary duodenal chick cells. The results demonstrated that the nanoAg were able to completely encapsulate the DNA, protected the $\mathrm{H} 5$ gene against DNase I and transferred the complex into primary cells as early as $1 \mathrm{~h}$ after transfection [82]. Moreover, single oral administration of DNA/H5 plasmid encapsulated in nanoAg in chickens induced antibodies and cell-mediated immune responses as well as enhanced cytokine production [20].

Biodegradability, increased immunogenicity, flexibility in conjugation with other molecules, including antibodies to specify the target delivery, and no involvement of live organisms (viruses or bacteria) in physical carriers have supported their potential to overtake biological carriers in the delivery of DNA vaccines. However, their cytotoxicity, safety (induction of nonspecific inflammation/allergic reaction) and capacity of DNA loading need to be further evaluated not only in vitro but also in field trials for veterinary vaccine delivery studies [83]. Currently, the most commonly used oral DNA vaccine delivery vehicles in poultry vaccination involve Salmonella species (70\%), LAB (20\%) and nanoparticles (10\%) (Figure 1C). 


\section{Conclusions}

DNA vaccination provided a new and valuable approach to the development of poultry vaccines and offered advantages in flexibility of design, speed, simplicity of production, and the ability to elicit both cellular and humoral immune responses. DNA vaccines against influenza in poultry have been in development since 1993, and recently, the USDA conditionally approved the first DNA vaccine against $\mathrm{H} 5 \mathrm{~N} 1$ for chickens. DNA vaccines are amendable for stockpiling to control future influenza H5N1 outbreaks. The pandemic AIV strains have undergone antigenic shift or drift, which allows them to avoid immunity elicited by the poultry influenza vaccines. Recent AIV vaccine development studies have indicated the need for additional systemic vaccine challenge studies against highly pathogenic AIV. Moreover, full protection has been demonstrated against poultry diseases, such as DTMUV, IBD, and ND. DNA vaccines also suffer from several pitfalls where in vivo efficacy and stability are still problems. Additionally, a single DNA vaccination in poultry is often insufficient to induce robust humoral and cell-mediated immunity as well as confer full protection. Therefore, booster immunization is often required. Both biological and physical carriers, with their appropriate antigens and adjuvants, offer the possibility to overcome the disadvantages of DNA vaccines. Although DNA vaccines carrying different antigens have been delivered by different types of carriers and adjuvants, very few have been evaluated by challenges with the pathogens in question. Thus, additional in vivo field trials should be carried out to identify the efficiency and safety of the currently available carriers, antigens, and adjuvants to combat infectious diseases of veterinary pathogens.

\begin{abstract}
Abbreviations
LAB: lactic acid bacteria; IM: intramuscular; USDA: The United States Department of Agriculture; AIV: avian influenza virus; APCs: antigen-presenting cells; DTMUV: duck Tembusu virus; IBDV: infectious bursal disease virus; NDV: Newcastle disease virus; IO: in ovo; ED: eye drop; IN: intranasal; CMV: cytomegalovirus; IBV: infectious bronchitis virus; CpG: cytosine-guanosine deoxynucleotide; Gl: gastrointestinal; HA: haemagglutinin; ARV: avian reovirus; DEV: duck enteritis virus; CAV: chicken anaemia virus; DCs: dendritic cells; PEI: polyethyleneimine; pDNA: plasmid DNA; PLGA: poly(lactide-co-glycolide); HI: haemagglutination inhibition; nanoAg: silver nanoparticles; pHEMA: poly(2hydroxyethyl methacrylate); GG: gene gun; Ref: references; ILTV: infectious laryngotracheitis virus; g: glycoprotein; REV: reticuloendotheliosis virus; TCoV: turkey coronavirus; DPV: duck plague virus; AVA: avian viral arthritis; PPs: Peyer's patches; CTs: caecal tonsils; VN: virus neutralization; S1: spike protein; N: nucleocapsid protein; M: membrane protein; IV: intravenous; IP: intraperitoneal; SC: subcutaneous; Ab: antibody; d: day; wk: week.
\end{abstract}

\section{Acknowledgements}

We would like to acknowledge the payment of publication cost by the School of Science and Technology, Sunway University.

\section{Authors' contributions}

SDJ designed the structure of the review, drafted the manuscript and prepared the figures and table, and CLP critically revised the manuscript. All authors read and approved the final manuscript.

\section{Funding}

This study was funded by the Sunway University Research Centre Grant (2019) to the Centre for Virus and Vaccine Research (CWR).

\section{Competing interests}

The authors declare that they have no competing interests.

Received: 11 April 2019 Accepted: 28 August 2019

Published online: 10 October 2019

References

1. Jarosz M, Jazowiecka-Rakus J, Cichon T, Glowala-Kosinska M, Smolarczyk R, Smagur A, Malina S, Sochanik A, Szala S (2013) Therapeutic antitumor potential of endoglin-based DNA vaccine combined with immunomodulatory agents. Gene Ther 20:262-273

2. Wolff JA, Malone RW, Williams P, Chong W, Acsadi G, Jani A, Felgner $P L$ (1990) Direct gene transfer into mouse muscle in vivo. Science 247:1465-1468

3. Davidson AH, Traub-Dargatz JL, Rodeheaver RM, Ostlund EN, Pedersen DD, Moorhead RG, Stricklin JB, Dewell RD, Roach SD, Long RE, Albers SJ, Callan RJ, Salman MD (2005) Immunologic responses to West Nile virus in vaccinated and clinically affected horses. J Am Vet Med Assoc 226:240-245

4. Garver KA, LaPatra SE, Kurath G (2005) Efficacy of an infectious hematopoietic necrosis (IHN) virus DNA vaccine in Chinook Oncorhynchus tshawytscha and sockeye O. nerka salmon. Dis Aquat Organ 64:13-22

5. Bergman PJ, Camps-Palau MA, McKnight JA, Leibman NF, Craft DM, Leung C, Liao J, Riviere I, Sadelain M, Hohenhaus AE, Gregor P, Houghton AN, Perales MA, Wolchok JD (2006) Development of a xenogeneic DNA vaccine program for canine malignant melanoma at the Animal Medical Center. Vaccine 24:4582-4585

6. Clynav, European Medicines Agency (2017) https://www.ema.europ a.eu/en/medicines/veterinary/EPAR/clynav. Accessed 11 Sept 2019

7. AgriLabs (2017) First DNA vaccine licensed for chickens. PR newswire: Cision. https://www.prnewswire.com/news-releases/first-dna-vacci ne-licensed-for-chickens-300554855.html

8. Robinson HL, Hunt LA, Webster RG (1993) Protection against a lethal influenza virus challenge by immunization with a haemagglutininexpressing plasmid DNA. Vaccine 11:957-960

9. Lim KL, Jazayeri SD, Yeap SK, Mohamed Alitheen NB, Bejo MH, Ideris A, Omar AR (2013) Antibody and T cell responses induced in chickens immunized with avian influenza virus N1 and NP DNA vaccine with chicken IL-15 and IL-18. Res Vet Sci 95:1224-1234

10. Oveissi S, Omar AR, Yusoff K, Jahanshiri F, Hassan SS (2010) DNA vaccine encoding avian influenza virus $\mathrm{H} 5$ and Esat- 6 of Mycobacterium tuberculosis improved antibody responses against AIV in chickens. Comp Immunol Microbiol Infect Dis 33:491-503

11. Jalilian B, Omar AR, Bejo MH, Alitheen NB, Rasoli M, Matsumoto S (2010) Development of avian influenza virus H5 DNA vaccine and MDP-1 gene of Mycobacterium bovis as genetic adjuvant. Genet Vaccines Ther 8:4

12. Sawant PM, Dhama K, Rawool DB, Wani MY, Tiwari R, Singh SD, Singh RK (2015) Development of a DNA vaccine for chicken infectious anemia and its immunogenicity studies using high mobility group box 1 protein as a novel immunoadjuvant indicated induction of promising protective immune responses. Vaccine 33:333-340

13. Rasoli M, Omar AR, Aini I, Jalilian B, Syed Hassan SH, Mohamed M (2010) Fusion of HSP70 gene of Mycobacterium tuberculosis to hemagglutinin (H5) gene of avian influenza virus in DNA vaccine enhances its potency. Acta Virol 54:33-39

14. Maity HK, Dey S, Mohan CM, Khulape SA, Pathak DC, Vakharia VN (2015) Protective efficacy of a DNA vaccine construct encoding the VP2 gene of infectious bursal disease and a truncated HSP70 of Mycobacterium tuberculosis in chickens. Vaccine 33:1033-1039 
15. Jiang Y, Yu K, Zhang H, Zhang P, Li C, Tian G, Li Y, Wang X, Ge J, Bu Z, Chen $\mathrm{H}$ (2007) Enhanced protective efficacy of H5 subtype avian influenza DNA vaccine with codon optimized HA gene in a pCAGGS plasmid vector. Antiviral Res 75:234-241

16. Ogunremi O, Pasick J, Kobinger GP, Hannaman D, Berhane Y, Clavijo A, van Drunen Littel-van den Hurk S (2013) A single electroporation delivery of a DNA vaccine containing the hemagg lutinin gene of Asian H5N1 avian influenza virus generated a protective antibody response in chickens against a North American virus strain. Clin Vaccine Immunol 20:491-500

17. Rao S, Kong WP, Wei CJ, Yang ZY, Nason M, Styles D, DeTolla LJ, Panda A, Sorrell EM, Song H, Wan H, Ramirez-Nieto GC, Perez D, Nabel GJ (2008) Multivalent HA DNA vaccination protects against highly pathogenic H5N1 avian influenza infection in chickens and mice. PLoS One 3:e2432

18. Shrestha A, Sadeyen JR, lqbal M (2018) Enhancing protective efficacy of poultry vaccines through targeted delivery of antigens to antigenpresenting cells. Vaccines 6:4

19. Jazayeri SD, Ideris A, Zakaria Z, Yeap SK, Omar AR (2012) Improved immune responses against avian influenza virus following oral vaccination of chickens with HA DNA vaccine using attenuated Salmonella typhimurium as carrier. Comp Immunol Microbiol Infect Dis 35:417-427

20. Jazayeri SD, Ideris A, Zakaria Z, Shameli K, Moeini H, Omar AR (2012) Cytotoxicity and immunological responses following oral vaccination of nanoencapsulated avian influenza virus H5 DNA vaccine with green synthesis silver nanoparticles. J Control Release 161:116-123

21. Li J, Jiang Y, Zhao S, Chang X, Liu J, Zeng X, Li Y, Chen H (2012) Protective efficacy of an H5N1 DNA vaccine against challenge with a lethal H5N1 virus in quail. Avian Dis 56:937-939

22. Lawman Z, Snider M, Wilson D, van den Hurk JV, Ellefsen B, Hannaman DJCVI (2013) Two doses of bovine viral diarrhea virus DNA vaccine delivered by electroporation induce long-term protective immune responses. Clin Vaccine Immunol 20:166-173

23. Azad N, Rojanasakul Y (2006) Vaccine delivery-current trends and future. Curr Drug Deliv 3:137-146

24. Zhai L, Wang Y, Yu J, Hu S (2014) Enhanced immune responses of chickens to oral vaccination against infectious bursal disease by ginseng stem-leaf saponins. Poult Sci 93:2473-2481

25. Jiao H, Pan Z, Yin Y, Geng S, Sun L, Jiao X (2011) Oral and nasal DNA vaccines delivered by attenuated Salmonella enterica serovar Typhimurium induce a protective immune response against infectious bronchitis in chickens. Clin Vaccine Immunol 18:1041-1045

26. Zhao K, Li W, Huang T, Luo X, Chen G, Zhang Y, Guo C, Dai C, Jin Z, Zhao Y, Guo C, Dai C, Jin Z, Zhao Y, Cui H, Wang Y (2013) Preparation and efficacy of Newcastle disease virus DNA vaccine encapsulated in PLGA nanoparticles. PLoS One 8:e82648

27. Lee CW, Senne DA, Suarez DL (2006) Development and application of reference antisera against 15 hemagglutinin subtypes of influenza virus by DNA vaccination of chickens. Clin Vaccine Immunol 13:395-402

28. Meunier M, Chemaly M, Dory D (2016) DNA vaccination of poultry: the current status in 2015. Vaccine 34:202-211

29. Stachyra A, Redkiewicz P, Kosson P, Protasiuk A, Gora-Sochacka A, Kudla G, Sirko A (2016) Codon optimization of antigen coding sequences improves the immune potential of DNA vaccines against avian influenza virus H5N1 in mice and chickens. Virol J 13:143

30. Kozak M (1987) At least six nucleotides preceding the AUG initiator codon enhance translation in mammalian cells. J Mol Biol 196:947-950

31. Cui HY, Wang YF, Shi XM, An TQ, Tong GZ, Lan DS, He L, Liu CJ, Wang M (2009) Construction of an infectious Marek's disease virus bacterial artificial chromosome and characterization of protection induced in chickens. J Virol Methods 156:66-72

32. Shan $S$, Jiang Y, Bu Z, Ellis T, Zeng X, Edwards J, Tian G, Li Y, Ge J, Chen H, Fenwick S (2011) Strategies for improving the efficacy of a H6 subtype avian influenza DNA vaccine in chickens. J Virol Methods 173:220-226

33. Taghavi A, Allan B, Mutwiri G, Van Kessel A, Willson P, Babiuk L, Potter A, Gomis S (2008) Protection of neonatal broiler chicks against Salmonella Typhimurium septicemia by DNA containing CpG motifs. Avian Dis 52:398-406

34. Sawant PM, Verma PC, Subudhi PK, Chaturvedi U, Singh M, Kumar R, Tiwari AK (2011) Immunomodulation of bivalent Newcastle disease DNA vaccine induced immune response by co-delivery of chicken IFNgamma and IL-4 genes. Vet Immunol Immunopathol 144:36-44
35. Huo S, Zhang J, Fan J, Wang X, Wu F, Zuo Y, Zhong F (2019) Co-expression of chicken IL-2 and IL-7 enhances the immunogenicity and protective efficacy of a VP2-expressing DNA vaccine against IBDV in chickens. Viruses 11:E476

36. Oshop GL, Elankumaran S, Vakharia VN, Heckert RA (2003) In ovo delivery of DNA to the avian embryo. Vaccine 21:1275-1281

37. Song X, Ren Z, Yan R, Xu L, Li X (2015) Induction of protective immunity against Eimeria tenella, Eimeria necatrix, Eimeria maxima and Eimeria acervulina infections using multivalent epitope DNA vaccines. Vaccine 33:2764-2770

38. Mackinnon KM, He H, Swaggerty $\mathrm{CL}$, McReynolds JL, Genovese KJ, Duke SE, Nerren JR, Kogut MH (2009) In ovo treatment with CpG oligodeoxynucleotides decreases colonization of Salmonella enteriditis in broiler chickens. Vet Immunol Immunopathol 127:371-375

39. Taghavi A, Allan B, Mutwiri G, Foldvari M, Van Kessel A, Willson P, Babiuk L, Potter A, Gomis S (2009) Enhancement of immunoprotective effect of CpG-ODN by formulation with polyphosphazenes against $E$. coli septicemia in neonatal chickens. Curr Drug Deliv 6:76-82

40. Abdul-Cader MS, Ahmed-Hassan H, Amarasinghe A, Nagy E, Sharif S, Abdul-Careem MF (2017) Toll-like receptor (TLR) 21 signalling-mediated antiviral response against avian influenza virus infection correlates with macrophage recruitment and nitric oxide production. J Gen Virol 98:1209-1223

41. Abdul-Cader MS, Amarasinghe A, Palomino-Tapia V, Ahmed-Hassan H, Bakhtawar K, Nagy E, Sharif S, Gomis S, Abdul-Careem MF (2018) In ovo CpG DNA delivery increases innate and adaptive immune cells in respiratory, gastrointestinal and immune systems post-hatch correlating with lower infectious laryngotracheitis virus infection. PLoS One 13:e0193964

42. Firouzamandi M, Moeini H, Hosseini SD, Bejo MH, Omar AR, Mehrbod P, El Zowalaty ME, Webster TJ, Ideris A (2016) Preparation, characterization, and in ovo vaccination of dextran-spermine nanoparticle DNA vaccine coexpressing the fusion and hemagglutinin genes against Newcastle disease. Int J Nanomedicine 11:259-267

43. Park JH, Sung HW, Yoon Bl, Kwon HM (2009) Protection of chicken against very virulent IBDV provided by in ovo priming with DNA vaccine and boosting with killed vaccine and the adjuvant effects of plasmid-encoded chicken interleukin-2 and interferon-gamma. J Vet Sci 10:131-139

44. Moreno M, Kramer MG, Yim L, Chabalgoity JA (2010) Salmonella as live trojan horse for vaccine development and cancer gene therapy. Curr Gene Ther 10:56-76

45. Schaffner W (1980) Direct transfer of cloned genes from bacteria to mammalian cells. Proc Natl Acad Sci U S A 77:2163-2167

46. Medina E, Guzman CA (2000) Modulation of immune responses following antigen administration by mucosal route. FEMS Immunol Med Microbiol 27:305-311

47. Drabner B, Guzman CA (2001) Elicitation of predictable immune responses by using live bacterial vectors. Biomol Eng 17:75-82

48. Dietrich G, Bubert A, Gentschev I, Sokolovic Z, Simm A, Catic A, Kaufmann SH, Hess J, Szalay AA, Goebel W (1998) Delivery of antigenencoding plasmid DNA into the cytosol of macrophages by attenuated suicide Listeria monocytogenes. Nat Biotechnol 16:181-185

49. Fennelly GJ, Khan SA, Abadi MA, Wild TF, Bloom BR (1999) Mucosal DNA vaccine immunization against measles with a highly attenuated Shigella flexneri vector. J Immunol 162:1603-1610

50. Shiau AL, Chu CY, Su WC, Wu CL (2001) Vaccination with the glycoprotein $D$ gene of pseudorabies virus delivered by nonpathogenic Escherichia coli elicits protective immune responses. Vaccine 19:3277-3284

51. Hense M, Domann E, Krusch S, Wachholz P, Dittmar KE, Rohde M, Wehland J, Chakraborty T, Weiss S (2001) Eukaryotic expression plasmid transfer from the intracellular bacterium Listeria monocytogenes to host cells. Cell Microbiol 3:599-609

52. Al-Mariri A, Tibor A, Lestrate P, Mertens P, De Bolle X, Letesson JJ (2002) Yersinia enterocolitica as a vehicle for a naked DNA vaccine encoding Brucella abortus bacterioferritin or P39 antigen. Infect Immun 70:1915-1923

53. Schoen C, Stritzker J, Goebel W, Pilgrim S (2004) Bacteria as DNA vaccine carriers for genetic immunization. Int J Med Microbiol 294:319-335

54. Mahmood MS, Hussain I, Siddique M, Akhtar M, Ali S (2007) DNA vaccination with VP2 gene of very virulent infectious bursal disease virus 
(VVIBDV) delivered by transgenic E. coli DH5alpha given orally confers protective immune responses in chickens. Vaccine 25:7629-7635

55. Revolledo L, Ferreira AJP (2012) Current perspectives in avian salmonellosis: vaccines and immune mechanisms of protection. J Appl Poultry Res 21:418-431

56. Chappell L, Kaiser P, Barrow P, Jones MA, Johnston C, Wigley P (2009) The immunobiology of avian systemic salmonellosis. Vet Immunol Immunopathol 128:53-59

57. Qu D, Yu H, Wang S, Cai W, Du A (2009) Induction of protective immunity by multiantigenic DNA vaccine delivered in attenuated Salmonella typhimurium against Toxoplasma gondii infection in mice. Vet Parasitol 166:220-227

58. Kubori T, Galan JE (2003) Temporal regulation of salmonella virulence effector function by proteasome-dependent protein degradation. Cell 115:333-342

59. Darji A, Guzman CA, Gerstel B, Wachholz P, Timmis KN, Wehland J, Chakraborty T, Weiss S (1997) Oral somatic transgene vaccination using attenuated S. typhimurium. Cell 91:765-775

60. Mastroeni P, Chabalgoity JA, Dunstan SJ, Maskell DJ, Dougan G (2001) Salmonella: immune responses and vaccines. Vet J 161:132-164

61. Li L, Fang W, Li J, Huang Y, Yu L (2006) Oral DNA vaccination with the polyprotein gene of infectious bursal disease virus (IBDV) delivered by the attenuated Salmonella elicits protective immune responses in chickens. Vaccine 24:5919-5927

62. Du A, Wang S (2005) Efficacy of a DNA vaccine delivered in attenuated Salmonella typhimurium against Eimeria tenella infection in chickens. Int J Parasitol 35:777-785

63. Higgs R, Cormican P, Cahalane S, Allan B, Lloyd AT, Meade K, James T, Lynn DJ, Babiuk LA, O'Farrelly C (2006) Induction of a novel chicken Toll-like receptor following Salmonella enterica serovar Typhimurium infection. Infect Immun 74:1692-1698

64. Jazayeri SD, Ideris A, Zakaria Z, Omar AR (2012) Attenuated Salmonella typhimurium SV4089 as a potential carrier of oral DNA vaccine in chickens. J Biomed Biotechnol 2012:8

65. Pan Z, Zhang X, Geng S, Cheng N, Sun L, Liu B, Huang J, Jiao X (2009) Priming with a DNA vaccine delivered by attenuated Salmonella typhimurium and boosting with a killed vaccine confers protection of chickens against infection with the $\mathrm{H} 9$ subtype of avian influenza virus. Vaccine 27:1018-1023

66. Wan J, Wang C, Wen X, Huang X, Ling S, Huang Y, Cao S (2011) Immunogenicity of a DNA vaccine of Avian Reovirus orally delivered by attenuated Salmonella typhimurium. Res Vet Sci 91:382-383

67. Yu X, Jia R, Huang J, Shu B, Zhu D, Liu Q, Gao X, Lin M, Yin Z, Wang M, Chen S, Wang Y, Chen X, Cheng A (2012) Attenuated Salmonella typhimurium delivering DNA vaccine encoding duck enteritis virus UL24 induced systemic and mucosal immune responses and conferred good protection against challenge. Vet Res 43:56

68. Huang J, Jia R, Shen H, Wang M, Zhu D, Chen S, Liu M, Zhao X, Wu Y, Yang Q, Yin Z, Cheng A (2018) Oral delivery of a DNA vaccine expressing the PrM and E genes: a promising vaccine strategy againstflavivirus in ducks. Sci Rep 8:12360

69. Mercenier A, Muller-Alouf H, Grangette C (2000) Lactic acid bacteria as live vaccines. Curr Issues Mol Biol 2:17-25

70. Dieye Y, Hoekman AJ, Clier F, Juillard V, Boot HJ, Piard JC (2003) Ability of Lactococcus lactis to export viral capsid antigens: a crucial step for development of live vaccines. Appl Environ Microbiol 69:7281-7288

71. Moeini H, Omar AR, Rahim RA, Yusoff K (2011) Improving the potency of DNA vaccine against chicken anemia virus (CAV) by fusing VP1 protein of CAV to Marek's Disease Virus (MDV) type-1 VP22 protein. Virol J 8:119

72. Wang Z, Yu Q, Fu J, Liang J, Yang Q (2013) Immune responses of chickens inoculated with recombinant Lactobacillus expressing the haemagglutinin of the avian influenza virus. J Appl Microbiol 115:1269-1277

73. Putnam D, Gentry CA, Pack DW, Langer R (2001) Polymer-based gene delivery with low cytotoxicity by a unique balance of side-chain termini. Proc Natl Acad Sci U S A 98:1200-1205

74. Hosseinkhani H, Aoyama T, Yamamoto S, Ogawa O, Tabata Y (2002) In vitro transfection of plasmid DNA by amine derivatives of gelatin accompanied with ultrasound irradiation. Pharm Res 19:1471-1479

75. Cui Z, Qiu F, Sloat BR (2006) Lecithin-based cationic nanoparticles as a potential DNA delivery system. Int J Pharm 313:206-213
76. Shim BS, Park SM, Quan JS, Jere D, Chu H, Song MK, Kim DW, Jang YS, Yang MS, Han SH, Park YH, Cho CS, Yun CH (2010) Intranasal immunization with plasmid DNA encoding spike protein of SARS-coronavirus/ polyethylenimine nanoparticles elicits antigen-specific humoral and cellular immune responses. BMC Immunol 11:65

77. Verminnen K, Beeckman DS, Sanders NN, De Smedt S, Vanrompay DC (2010) Vaccination of turkeys against Chlamydophila psittaci through optimised DNA formulation and administration. Vaccine 28:3095-3105

78. Negash T, Liman M, Rautenschlein S (2013) Mucosal application of cationic poly(D, L-lactide-co-glycolide) microparticles as carriers of DNA vaccine and adjuvants to protect chickens against infectious bursal disease. Vaccine 31:3656-3662

79. Huang JL, Yin YX, Pan ZM, Zhang G, Zhu AP, Liu XF, Jiao XA (2010) Intranasal immunization with chitosan/pCAGGS-flaA nanoparticles inhibits Campylobacter jejuni in a White Leghorn model. J Biomed Biotechnol 2010:589476

80. Zhang W, Yin Z, Liu N, Yang T, Wang J, Bu Z, Wu D (2010) DNA-chitosan nanoparticles improve DNA vaccine-elicited immunity against Newcastle disease virus through shuttling chicken interleukin-2 gene. J Microencapsul 27:693-702

81. Gong Q, Kong LY, Niu MF, Qin CL, Yang Y, Li X, Ruan MD, Tian Y, Li ZL (2018) Construction of a ptfA chitosan nanoparticle DNA vaccine against Pasteurella multocida and the immune response in chickens. Vet J 231:1-7

82. Jazayeri SD, Ideris A, Shameli K, Moeini H, Omar AR (2013) Gene expression profiles in primary duodenal chick cells following transfection with avian influenza virus H5 DNA plasmid encapsulated in silver nanoparticles. Int J Nanomedicine 8:781-790

83. Shim G, Kim M-G, Park JY, Oh Y-K (2013) Application of cationic liposomes for delivery of nucleic acids. Asian J Pharm Clin Res 8:72-80

84. Redding L, Werner DB (2009) DNA vaccines in veterinary use. Expert Rev Vaccines 8:1251-1276

85. Yan F, Zhao Y, Hu Y, Qiu J, Lei W, Ji W, Li X, Wu Q, Shi X, Li Z (2013) Protection of chickens against infectious bronchitis virus with a multivalent DNA vaccine and boosting with an inactivated vaccine. J Vet Sci $14: 53-60$

86. Poinern GE, Le XT, Shan S, Ellis T, Fenwick S, Edwards J, Fawcett D (2011) Ultrasonic synthetic technique to manufacture a pHEMA nanopolymeric-based vaccine against the H6N2 avian influenza virus: a preliminary investigation. Int J Nanomedicine 6:2167-2174

87. Sun K, Li X, Jiang J, Cheng A, Wang M, Zhu D, Jia R, Chen S, Zhou Y, Chen $X$, Zhou Y, Chen X, Wang X (2013) Distribution characteristics of DNA vaccine encoded with glycoprotein C from Anatid herpesvirus 1 with chitosan and liposome as deliver carrier in ducks. Virol J 10:89

88. Sakaguchi M, Nakamura H, Sonoda K, Hamada F, Hirai K (1996) Protection of chickens from Newcastle disease by vaccination with a linear plasmid DNA expressing the F protein of Newcastle disease virus. Vaccine 14:747-752

89. Xu J, Zhang Y, Tao J (2013) Efficacy of a DNA vaccine carrying Eimeria maxima Gam56 antigen gene against coccidiosis in chickens. Korean J Parasitol 51:147-154

90. Zhao K, Zhang Y, Zhang X, Li W, Shi C, Guo C, Dai C, Chen Q, Jin Z, Zhao Y, Cui H, Wang Y (2014) Preparation and efficacy of Newcastle disease virus DNA vaccine encapsulated in chitosan nanoparticles. Int J Nanomedicine 9:389-402

91. Li K, Gao L, Gao H, Qi X, Gao Y, Qin L, Wang Y, Wang X (2013) Protection of chickens against reticuloendotheliosis virus infection by DNA vaccination. Vet Microbiol 166:59-67

92. Gong Q, Qu N, Niu M, Qin C, Cheng M, Sun X, Zhang A (2013) Immune responses and protective efficacy of a novel DNA vaccine encoding outer membrane protein of avian Pasteurella multocida. Vet Immunol Immunopathol 152:317-324

93. Song X, Zhao X, Xu L, Yan R, Li X (2017) Immune protection duration and efficacy stability of DNA vaccine encoding Eimeria tenella TA4 and chicken IL-2 against coccidiosis. Res Vet Sci 111:31-35

94. Zhao Y, Cao Y, Cui L, Ma B, Mu X, Li Y, Zhang Z, Li D, Wei W, Gao M, Wang $J$ (2014) Duck enteritis virus glycoprotein D and B DNA vaccines induce immune responses and immunoprotection in Pekin ducks. PLoS One 9:e95093

95. Chen YN, Wu CC, Yeo Y, Xu P, Lin TL (2013) A DNA prime-protein boost vaccination strategy targeting turkey coronavirus spike protein 
fragment containing neutralizing epitope against infectious challenge. Vet Immunol Immunopathol 152:359-369

96. Shi W, Liu Q, Zhang J, Sun J, Jiang X, Geng J, Wang F, Xiao Y, Li H, Zhao X (2014) Co-expression of EtMic2 protein and chicken interleukin-18 for DNA vaccine against chicken coccidiosis. Res Vet Sci 97:64-70

97. Lian B, Cheng A, Wang M, Zhu D, Luo Q, Jia R, Liu F, Han X, Chen X (2011) Induction of immune responses in ducks with a DNA vaccine encoding duck plague virus glycoprotein C. Virol J 8:214

98. Muneta Y, Panicker IS, Kanci A, Craick D, Noormohammadi AH, Bean A, Browning GF, Markham PF (2008) Development and immunogenicity of recombinant Mycoplasma gallisepticum vaccine strain ts-11 expressing chicken IFN-gamma. Vaccine 26:5449-5454

99. Kodihalli S, Haynes JR, Robinson HL, Webster RG (1997) Cross-protection among lethal H5N2 influenza viruses induced by DNA vaccine to the hemagglutinin. J Virol 71:3391-3396

100. Guionie O, Niqueux E, Amelot M, Bougeard S, Jestin V (2014) H5-based DNA constructs derived from selected highly pathogenic H5N1 avian influenza virus induce high levels of humoral antibodies in Muscovy ducks against low pathogenic viruses. Virol J 11:74

101. Babapoor S, Almeida DdO, Fabis JJ, Helal ZH, Wang X, Girshick T, Khan MIJIJPS (2009) Protective effect of In ovo vaccination with IBV-spikerecombinant DNA and chicken interferon as an adjuvant. Int J Poult Sci 11:1034-1041

102. Weiss S, Krusch S (2001) Bacteria-mediated transfer of eukaryotic expression plasmids into mammalian host cells. Biol Chem 382:533-541

103. Hosseinkhani H (2006) DNA nanoparticles for gene delivery to cells and tissue. Int J Nanotechnol 3:416-461

\section{Publisher's Note}

Springer Nature remains neutral with regard to jurisdictional claims in published maps and institutional affiliations.
Ready to submit your research? Choose BMC and benefit from:

- fast, convenient online submission

- thorough peer review by experienced researchers in your field

- rapid publication on acceptance

- support for research data, including large and complex data types

- gold Open Access which fosters wider collaboration and increased citations

- maximum visibility for your research: over $100 \mathrm{M}$ website views per year

At BMC, research is always in progress.

Learn more biomedcentral.com/submissions 